\title{
Um estudo sobre o uso anafórico das descrições definidas no discurso ${ }^{1}$
}

\author{
A study on the anaphoric use of definite descriptions \\ in discourse
}

\section{Gabriel de Ávila Othero Pontifícia Universidade Católica do Rio Grande do Sul} Resumo

Acreditamos que, em português, o uso anafórico das descrições definidas ainda não foi estudado detalhadamente e, por isso, merece atenção. Aqui sistematizamos as ocorrências das anáforas envolvendo descrições definidas no discurso em português. Analisamos grande variedade de casos em que uma descrição definida é usada em um processo anafórico no discurso. As descrições definidas, para o âmbito deste trabalho, serão aqueles sintagmas nominais que começam por um artigo definido (em português, $o$ e $a$ e seus respectivos plurais, os e as).

\section{Palavras-chave}

Correferência, Descrições definidas, Referenciação

\section{Abstract}

We believe that, in Portuguese, the anaphoric resolution of definite descriptions has not yet been scrutinized. In this article, we intend to analyze and classify a large number of cases in which the definite description is used in an anaphoric process. We will consider definite expressions here as those noun phrases that begin with a definite article ( $o$ and $a$ and their respective plural forms, os and $a s$ ).

\section{Keywords}

Correference, Definite Descriptions, Reference 


\section{Introdução}

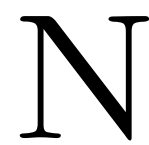

este artigo, pretendemos fazer uma descrição pormenorizada e detalhada do uso anafórico das descrições definidas em texto escrito.

sintagmas nominis que começam por umartigo definido (emportuguês, oea e seus respectivos plurais, $o s$ e $a s) .^{2}$ Exemplos:

(1) José Sarney teve um sonho confuso. Um telefone tocava em algum lugar do palio. (LFV1)

(2) Um dia ele chegou com um robô. $O$ robô era baixinho. (LFV2)

Nos exemplos (1) e (2), as expressões destacadas são descrições definidas. De acordo com a tradição gramatical, esse tipo de expressão serve para retomar entidades já mencionadas no texto, ou supostamente conhecidas do interlocutor por estarem no contexto de comunicação. ${ }^{3}$

Enfocaremos aqui as descrições definidas que são usadas anaforicamente no contexto discursivo. Nossa análise será sempre ilustrada com exemplos de textos autênticos do português brasileiro, extraídos de jornais, revistas, livros técnicos e narrativas. ${ }^{4}$ Com este trabalho, pretendemos sistematizar o uso das descrições definidas em processos anafóricos discursivos; iremos estudar uma grande variedade de casos em que uma descrição definida é usada em um processo anafórico no discurso.

\section{Os Usos Anafóricos das Expressões Definidas}

A correferenciação e a referenciação são elementos essenciais na coesão textual, responsáveis pela progressão do texto. Veremos que a correferenciação será especialmente importante em nossa análise do uso anafórico das descrições definidas em um texto. ${ }^{5}$ Os processos de correferenciação e referenciação reativam referentes já mencionados ou ativam novos referentes ancorados em 
outros já conhecidos. As descrições podem ter antecedentes (correferentes) ou âncoras (referentes) textuais, ou seja, as descrições definidas podem ser usadas em processos de correferência e de referência no discurso. Para sistematizar as relações anafóricas envolvendo as descrições definidas, resolvemos dividir essas relações em quatro grandes tipos: anáfora direta, anáfora valorativa, anáfora associativa e anáfora conceitual.

\subsection{Anáfora Direta}

Nos casos de anáfora direta, há uma relação de correferência entre a descrição definida e seu antecedente, ou seja, ambos se referem à (ou apontam para a) mesma entidade discursiva. Além do mais, na anáfora direta, o mesmo item lexical é repetido tanto no núcleo do sintagma nominal antecedente como no termo anafórico. Exemplo:

(3) Um dia ele chegou com um robo $\hat{\mathrm{i}}_{\mathrm{i}}$ O robo $_{\mathrm{i}}$ era baixinho. (LFV2)

Encontramos em Marcuschi (2001,p. 2) a seguinte definição de anáforas diretas:

Em geral, postula-se que as $\boldsymbol{A D}$ [anáforas diretas] retomam referentes previamente introduzidos, ou seja, estabeleceriam uma relação de correferência entre o elemento anafórico e seu antecedente. Parece haver uma equivalência semântica e sobretudo uma identidade referencial entre a anáfora e seu antecedente. (...) Pode-se dizer que a visão clássica da anáfora direta se dá com base na noção de que a anáfora é um processo de reativação de referentes prévios. ${ }^{7}$ (grifos do autor)

Em geral, nas anáforas diretas, uma entidade é introduzida no discurso com umartigo indefinidoe mais adianteé retomada por uma descrição definida, como vimos em (3). Há casos, no entanto, em que a anáfora direta ocorre entre duas descrições definidas, exemplo (4), ou mesmo entre uma descrição definida e um elemento anteriormente mencionado que não é precedido por artigo algum, como em (5).

(4) O tatu se enfiou dentro de sua toca, onde estava toda sua família. Entrou apressado, como quem vem fugindo de alguma coisa. De fato, ele viu por perto um leão e, embora soubesse que ele prefere 


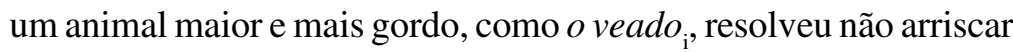
e sair da vista do caçador. Não muito longe, $o$ veado, ao perceber que havia um leão rondando por ali, saiu em disparada, correndo pra valer. (FAB)

(5) Olhe, eu podia mesmo contar-lhe a minha vida inteira, em que há outras cousas interessantes, mas para isso era preciso tempo ${ }_{\mathrm{i}}$, ânimo $_{\mathrm{j}}$ e papel, e eu só tenho papel; $o$ ânimo $_{\mathrm{j}}$ é frouxo, e o tempo $o_{\mathrm{i}}$ assemelha-se à lamparina de madrugada. (MA)

Em relação à carga semântica das anáforas diretas, elas podem ser divididas em duas classes:

(a) Sem modificação na carga semântica do referente: o nome-núcleo do antecedente se repete na descrição definida, e não há alteração alguma de significado, ou seja, nenhuma propriedade é atribuída à entidade referida na retomada anafórica. Exemplos:

(6) Todos diziam que a Leninha, quando crescesse, ia ser médica. Passava horas brincando de médico com as bonecas $_{\mathrm{i}}$. Só que, ao contrário das outras crianças, quando largou as bonecas , , não perdeu a mania. (LFV2)

(7) Os sábios sabem, os que dialogam na praça pública não sabem, por isto se chamam filósofos, amantes da sabedori $a_{\mathrm{i}}$, e porque $a$ sabedoria $_{\mathrm{i}}$ não se rende a seus assédios, são amantes insatisfeitos. (DS)

Repare que os nomes-núcleo foram simplesmente retomados pela descrição definida sem que nenhum acréscimo de significado fosse efetuado no sintagma nominal a que pertencem.

b) Com modificação na carga semântica do referente: o nome-núcleo do antecedente se repete na descrição definida e há alteração de significado, por uma supressão de termos que se referem àquela entidade retomada pela descrição definida. Exemplos:

(8) Tudo começa quando um jovem cientist $a_{\mathrm{i}}$ realiza um experimento com um acelerador de partículas. (...) E o jogador deve ter cuidado: um passo errado significa a morte do cientista $_{\mathrm{i}}$. (RCG) 
(9) No século XVII, Isaac Newton mudou a ciência ao descobrir que alguns fenômenos da natureza poderiam ser explicados com leis matemáticas . A partir daí, muitos pesquisadores acreditaram que as leis $_{\mathrm{i}}$ poderiam explicar e prever o comportamento de todos os fenômenos se fossem reunidas informações suficientes. (SUP)

Nesses casos, há uma supressão de informações quando se dá a anáfora pela descrição definida. $\mathrm{O}$ item lexical se repete na expressão definida, porém seus modificadores não são mais mencionados. Em (9), um jovem cientista é retomado simplesmente por o cientista, e em (10) leis matemáticas é retomado pela descrição definida as leis.

\subsection{Anáfora Valorativa ${ }^{8}$}

Neste segundo tipo de anáfora, a descrição definida também mantém uma relação de correferência com seu antecedente, porém não há mais uma identidade lexical entre os dois, ou seja, o nome-núcleo do antecedente não é retomado pelo termo anafórico. ${ }^{9}$

A principal diferença entre a anáfora direta e a valorativa pode ser visualizada na seguinte tabela:

TABELA1

Anáfora direta $\mathrm{x}$ anáfora valorativa

\begin{tabular}{l|c|c}
\hline & Nome-núcleo & Entidade referida \\
\hline Anáfora Direta & $=$ & $=$ \\
Anáfora Valorativa & $\neq$ & $=$ \\
\hline
\end{tabular}

Nas anáforas valorativas, assim como nas diretas, em geral uma entidade é introduzida no discurso com um artigo indefinido e mais adiante é retomada por uma descrição definida. Nas anáforas valorativas, o nome-núcleo da descrição definida é diferente do nome-núcleo de seu antecedente. O termo valorativo, em semântica, pode ser aplicado a uma expressão que atribui certo valor subjetivo a um determinado fato. Por exemplo, na frase João lamentou ter deixado a escola, o verbo de sensação (lamentar) também é valorativo, pois não apenas pressupõe que João deixou a escola, como também atribui um valor a esse fato. Essa frase, na verdade, pressupõe duas proposições: 
a) João deixou a escola;

b) João ter feito isso não foi algo positivo. ${ }^{10}$

Como veremos mais adiante, nem sempre o termo anafórico reflete uma opinião clara do locutor; porém, a descrição definida em uma anáfora valorativa sempre irá mostrar uma escolha lexical feita diretamente por ele. Daí adotarmos o nome "anáfora valorativa": a escolha de um novo item lexical para o termo anafórico revela, em maior ou menor grau, o valor que o locutor do texto tem com relação à entidade mencionada.

Apesar de Koch (1997) não abordar este tipo de anáfora especificamente, nem usar a nomenclatura que propomos aqui, ela diz o seguinte sobre este tipo de substituição lexical em anáforas lexicais:

(...) o uso de uma expressão definida implica sempre uma escolha dentre as propriedades ou qualidades que caracterizam o referente, escolha esta que será feita de acordo com aquelas propriedades ou qualidades que, em dada situação de interação, em função dos propósitos a serem atingidos, o produtor do texto tem interesse em ressaltar, ou mesmo tornar conhecidas de seu(s) interlocutor(es). (...) [A] escolha das descrições definidas pode trazer ao interlocutor informações importantes sobre as opiniões, crenças e atitudes do produtor do texto, auxiliando-o na construção do sentido $(\mathrm{KOCH}$, 1997, p. 43).

Para ilustrar, a autora apresenta os seguintes exemplos:

(10) Reagan ${ }_{\mathrm{i}}$ perdeu a batalha no Congresso. O presidente americano $_{\mathrm{i}}$ não tem tido grande sucesso ultimamente em suas negociações com o Parlamento.

(11) Reagan $n_{\mathrm{i}}$ perdeu a batalha no Congresso. O cowboy do faroeste americano $_{\mathrm{i}}$ não tem tido grande sucesso ultimamente em suas negociações com o Parlamento.

No exemplo (10), Reagan é retomado por uma descrição definida pragmaticamente discreta, que apenas especifica/esclarece quem é o referente. No exemplo (11), no entanto, Reagan tem como correferente um epíteto que demonstra de maneira visível como o locutor do texto vê o referente e como ele 
deseja mostrá-lo ao seu interlocutor-como um cowboy do faroeste americano. Em uma anáfora valorativa, o nome-núcleo da descrição definida deixa transparecer uma escolha lexical do produtor do texto, deixando às vezes claramente expressos seus valores de juízo sobre o referente. Outro exemplo interessante vem de Clark (1979, p. 414):

(12) Eu conheci um cara $_{\mathrm{i}}$ ontem. O desgraçado roubou todo o meu dinheiro. ${ }^{11}$

Em (12), o interlocutor também deixa uma forte impressão subjetiva sobre o referente um cara. Outros exemplos:

(13) Billie Holiday morreu aos 44 anos $_{\mathrm{i}}$. A pouca idade pão significa $_{\mathrm{i}}$ que haja pequena quantidade de material gravado com a voz inconfundível e a interpretação única. (FSP)

(14) Billie Holiday i $_{\mathrm{i}}$ orreu aos 44 anos. (...) Para conhecer a vida $\mathrm{d} a$ diva $_{\mathrm{i}}$, ouvir canções em MP3 e trechos da autobiografia "Lady Sings the Blues", entre no site não oficial, o www.ladyday.net. (FSP)

No exemplo (13), o locutor deixa entender que 44 anos é uma idade prematura para que alguém morra; enquanto em (15), ele mostra sua opinião sobre o referente ativado com Billie Holliday. Para o produtor do texto, em (13) 44 anos = pouca idade (para morrer); e em (14) Billie Holliday = diva.

Entretanto, como dissemos, nem sempre essa opinião do locutor fica tão fortemente gravada na escolha lexical do termo anafórico. Vejamos outros casos de anáfora valorativa em que a relação entre os substantivos envolvidos no processo apresentam outro tipo de relação semântica.

\subsubsection{Explicação/Esclarecimento}

Muitas vezes, uma entidade é referida no texto e mais adiante é retomada por uma anáfora valorativa que dá mais informações ao interlocutor, esclarecendo, explicando ou tornando ainda mais claro o referente mencionado. De acordo com Koch (1999, p. 140),

verifica-se, portanto, que a escolha de determinada descrição definida pode trazer ao leitor/ouvinte informações importantes sobre as opiniões, crenças e atitudes do produtor do texto, auxiliando-o na 
construção do sentido. Por outro lado, contudo, o locutor pode ter o objetivo de, através do uso de uma descrição definida, dar a conhecer ao interlocutor, com os mais variados propósitos, propriedades ou fatos relativos ao referente que acredita desconhecidos do parceiro.

O item lexical escolhido pelo locutor em uma anáfora desse tipo vem a ajudar na caracterização mental da entidade referida na construção de sentidos do seu interlocutor. Exemplos:

(15) Maior do que a dor de cabeça dos estudantes para decorar a tabela periódica foi a dificuldade que Mendeleiev $_{\mathrm{i}}$ teve em montá-la. Embora tivesse todas as informações das quais precisava - os elementos químicos e suas propriedades -, o químico russo ${ }_{\mathrm{i}}$ não conseguia distribuí-los de maneira ordenada. (SUP)

(16) Em tom parodisíaco, Aristófanes ${ }_{\mathrm{i}}$ narra o malogro de Anfítheos, removido da assembleia ao declarar seus objetivos. Anfítheos (um nome cômico: Deus de ambos os lados) mostra a ineficácia em conflitos reais das fantásticas soluções do tragedista $_{\mathrm{i}}$. (DS)

O interlocutor pode não conseguir conhecer os referentes Mendeleiev e Aristófanes. Por isso, uma estratégia do locutor é adicionar outras informações ao referente quando de sua retomada por uma anáfora valorativa. Além de servir na progressão e coesão textuais, a anáfora valorativa auxilia na compreensão da coerência do texto, auxiliando o interlocutor através de uma retomada explicativa, que apresenta mais características da entidade que está sendo retomada. Assim, é possível estabelecer as seguintes relações: em (15) Mendeleiev = químico russo; e em (16) Aristófanes = tragedista.

\subsubsection{Anáfora Hiponímica}

A anáfora valorativa explicativa também pode ser entendida como uma anáfora hiponímica. Em um processo de substituição por hiponímia, primeiro o locutor insere um termo mais específico no discurso, para então retomá-lo com uma expressão mais geral, em uma relação parte/todo. $\mathrm{O}$ antecedente tem como nome-núcleo um item lexical que apresenta essa relação parte/todo com seu termo anafórico. A descrição definida vem a ser, então, um hiperônimo de seu antecedente, enquanto este é seu hipônimo. 
De acordo com Ilari \& Geraldi (1994, p. 88), a hiponímia "é uma relação de sentido que se estabelece entre um termo específico e um termo mais". Nesse tipo de anáfora, a relação entre o antecedente e a descrição definida é $X$ é um $Y$, onde $\mathrm{X}$ é o antecedente e $\mathrm{Y}$ o termo anafórico.

Em geral, a substituição lexical se dá por meio de expressões cada vez mais abrangentes, ou seja, a descrição definida é hiperônimo de seu antecedente. De acordo com Fávero (1997), a relação de hiponímia é possível porque, na estrutura profunda semântico-lexical, há uma definição ou uma inclusão de traços semânticos que vão do termo mais particular para o mais geral. Exemplos:

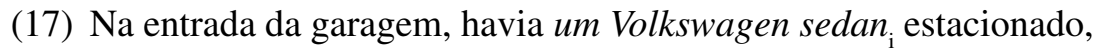
encostado numa caminhonete. Pela posição do carro $_{\mathrm{i}}$, Pedro percebeu que não conseguiria entrar em casa. Pôs-se então a buzinar furiosamente, esperando que o proprietário do veículo ${ }_{\mathrm{i}}$ aparecesse. (Exemplo de ILARI \& GERALDI, 1994, p. 53.)

(18) O tatu se enfiou dentro de sua toca, onde estava toda sua família. Entrou apressado, como quem vem fugindo de alguma coisa. De fato, ele viu por perto um leão $\mathrm{e}$, embora soubesse que ele prefere um animal maior e mais gordo, como o veado, resolveu não arriscar e sair da vista do caçador $_{\mathrm{i}}$. (FAB)

Em (17) e (18), podemos ver uma progressão referencial, vinda do menos abrangente (ou mais específico) ao mais abrangente (ou menos específico). As relações semânticas mantidas entre os itens lexicais são as seguintes: em (17) um Volkswagen sedan é um carro, e um carro é um veículo; e em (18) um leão é um caçador.

\subsubsection{Anáfora Hiperonímica}

Menos comum é a substituição lexical se realizar por um processo contrário ao da hiponímia, ou seja, pelo processo de hiperonímia. De acordo com Guimarães (1993, p. 31-32), "dá-se a hiperonímia quando a primeira expressão mantém com a segunda uma relação todo/parte" (grifos da autora). Na relação de substituição por hiperonímia, ao contrário da anterior, a relação entre antecedente e termo anafórico é $Y$ é um $X$, onde Y é o termo anafórico e $\mathrm{X}$ é o antecedente. Nesse tipo de anáfora valorativa, o antecedente é, então, uma 
expressão superordenada em relação à descrição definida que lhe serve de termo anafórico. A progressão vai do mais abrangente ao menos abrangente. Exemplos:

(19) Há 35 anos, o jazz perdeu um de seus maiores sax tenores. John Coltrane morreu aos 40 anos, de câncer no fígado. (...) A página oficial tem vídeo de performance do músico $o_{\mathrm{i}}$ informações sobre a fundação que leva seu nome. (...) Em www.jcmc.neu.edu, o internauta encontra a história do jazzista $a_{\mathrm{i}}$, que começou a tocar com Miles Davis em 1955 (...) (FSP)

(20) $A$ peça $a_{\mathrm{i}}$ era um dramalhão, cosido a facadas, ouriçado de imprecações e remorsos; mas Fortunato ouviu-a com singular interesse. (...) No fim do drama, veio uma farsa. (MA)

Repare que, nos exemplos (19) e (20), a progressão se dá do termo mais geral ao mais específico. A relação entre antecedente e termo anafórico em (19) e (20) é a seguinte: em (19) jazzista é um músico; e em (20) drama é uma peça. Essa relação de hiperonímia é bem menos comum, e muitos estudiosos julgamna "incompreensível", "insólita", ou até mesmo a ignoram. ${ }^{12}$ Porém, como tentamos mostrar, ela efetivamente acontece. Em ambos os exemplos essa relação aconteceu sem nenhum problema de processamento ou estranhamento, mas devemos reconhecer que havia outros elementos, externos à relação de correferenciação entre os termos, que ajudaram na compreensão do fenômeno. Em (19), o termo Jazz é ativado antes de jazzista e de músico; e em (20), dramalhão é ativado antes da descrição definida o drama. Isso parece facilitar a compreensão deste tipo de anáfora

\subsubsection{Substituição por Sinonímia}

Em casos de anáfora valorativa, às vezes a troca de item lexical deve-se a questões de estilo, para que não haja demasiadas repetições dos mesmos substantivos ao longo do texto. Nesses casos, uma escolha do locutor é retomar o referente, alterando o item lexical por outro que lhe sirva de sinônimo contextual. Ainda que pareça neutra, a escolha de outro item lexical para a retomada do referente é feita única e exclusivamente pela motivação do produtor do texto, revelando ao interlocutor, portanto, uma escolha subjetiva. Exemplos: 
(21) Out of this world é um game ${ }_{\mathrm{i}}$ cativante. É quase um adventure, mas todas as cenas são recheadas da mais pura ação. (...) Os cenários são bastante insólitos: as paisagens são tomadas por excessos de tons azuis, que combinam perfeitamente com o clima do jogo $o_{\mathrm{i}}$ (RCG)

(22) Quantos minutos você já perdeu na fila do banco e, ao ser atendido, ainda teve de agüentar o mau humor do caixa? (...) Pode não ser o seu caso, mas contratempos como esses já fizeram muita gente passar a mão no telefone ou mandar um e-mail ao Banco Central ${ }_{\mathrm{i}}$, reclamando de coisas assim. $O B C_{\mathrm{i}}$ registra os resmungos e faz uma análise dos problemas de cada banco no país. (REX)

Em (21), game e jogo podem ser considerados sinônimos naquele contexto comunicativo, assim como em (22), Banco Central e $B C$ são sinônimos, pois são duas formas intercambiáveis de se referir à mesma entidade discursiva. ${ }^{13}$

\subsubsection{Recurso Estilístico}

Para evitar a repetição lexical, o locutor também pode se valer de alguns recursos estilísticos, utilizando as descrições definidas o último, o primeiro, $o$ outro, o mesmo, etc. Como podemos ver nos exemplos (23), (24) e (25):

(23) Garcia tinha-se formado em medicina, no ano anterior, 1861 . No ano de 1860, estando ainda na escola, encontrou-se com Fortunato $_{\text {, }}$, pela primeira vez, à porta da Santa Casa; entrava, quando 0 outro saía. (MA)

(24) Antes de entrar no elevador ${ }_{\mathrm{i}}$, certifique-se de que o mesmo ${ }_{\mathrm{i}}$ esteja parado neste andar. (frase retirada de uma placa de elevador)

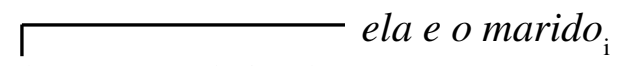

(25) Ela sentou na beira da cama. Protestou, chorosa, quando o marido disse que sabia que estava no fim. (...) Os dois sabiam que ele tinha pouco tempo de vida e era melhor que enfrentassem a situação sem drama. (LFV2)

Como vimos, a anáfora valorativa não é utilizada simplesmente para evitar repetição lexical; ela pode revelar o julgamento de valor que o locutor do texto tem a respeito do referente, além de poder servir como um esclarecimento na retomada dele. 


\subsection{Anáfora Associativa}

A classe das anáforas associativas é, talvez, a mais complexa. Uma resolução anafórica desse tipo envolve complexas associações mentais que, muitas vezes, podem ir além do conhecimento linguístico estrito, valendo-se de processos cognitivos e relações pragmáticas entre os termos que compõem a anáfora. Schwarz (2000) traz uma definição clara sobre as anáforas associativas (as quais ela chama de anáforas indiretas):

(...) trata-se de expressões definidas que se acham na dependência interpretativa em relação a determinadas expressões da estrutura textual precedente e que têm duas funções referenciais textuais: a introdução de novos referentes (até aí não nomeados explicitamente) e a continuação da relação referencial global. (Apud MARCUSCHI, 2001, p. 221)

A maior diferença entre as relações anafóricas correferenciais e a anáfora associativa é que as primeiras têm uma relação de identidade correferencial com seu antecedente, enquanto esta última introduz um elemento novo no mundo discursivo, reativando através dele elementos anteriores e ancorando sua existência nesses elementos já conhecidos do interlocutor. Para Marcuschi (2001, p. 221), o fenômeno da anáfora associativa é "uma espécie de ação remática e temática simultaneamente na medida em que traz a informação nova e velha, ou seja, produz uma 'tematização remática"' (grifos do autor). Exemplo:

(26) Entrei em um restaurante, e o garçom veio me atender.

No exemplo (26), a descrição definida $o$ garçom não apresenta nenhum antecedente, porém está ancorada em um termo anterior, que é reativado por essa expressão definida. A esse termo anterior chamaremos de âncora textual ${ }^{14}, \mathrm{e}$ essa relação será chamada de anáfora associativa. Aqui, o termo anafórico não apresenta uma identidade correferencial com sua âncora textual, e seu nomenúcleo pode ser o mesmo ou outro que aquele usado pela âncora. Por isso, essa relação, ao contrário das estudadas anteriormente, não é de correferenciação, mas de referenciação, ou seja, a descrição definida não retoma seu antecedente, ela apenas está relacionada com ele de alguma forma. Isso nos permite elaborar a seguinte tabela: 
TABELA 2

Diferenças entre anáfora direta, valorativa e associativa

\begin{tabular}{l|c|c}
\hline & Nome-núcleo & Entidade referida \\
\hline Anáfora Direta & $=$ & $=$ \\
Anáfora Valorativa & $\neq$ & $=$ \\
Anáfora Associativa & $=$ & $\neq$ \\
& $\neq$ & $\neq$ \\
\hline
\end{tabular}

Nos casos de anáfora associativa, adotamos outro tipo de identificação gráfica dos termos envolvidos na resolução anafórica: a descrição definida que serve de termo anafórico ganha o índice referencial ${ }_{r}$ subscrito (de item referencial), e a âncora textual recebe o índice ${ }_{\mathrm{a}}$ subscrito, seguindo as propostas de Haag \& Othero (2003).

De acordo com Marcuschi (2001, p. 217), a anáfora associativa é "uma estratégia endofórica de ativação de referentes novos e não de reativação de referentes já conhecidos, o que constitui um processo de referenciação implícita" (grifos do autor). Esse processo extrapola o conceito estrito de anáfora, pois prevê uma ligação semântica ou pragmática entre dois itens lexicais que fazem referência a diferentes entidades discursivas, mantendo, no entanto, uma estreita ligação. A anáfora associativa, ainda segundo Marcuschi (2001, p. 217),

representa um desafio teórico e obriga a abandonar a maioria das noções estreitas de anáfora, impedindo que se continue confinando-a ao campo dos pronomes e da referência em sentido estrito. Ameaça noções de texto e coerência hoje no mercado, constituindo um problema central para as teorias formais da referência (...). Por fim, reintroduz no contexto da gramática aspectos sociocognitivos relevantes que permitem repensar tópicos gramaticais na interface com a semântica e a pragmática.

Em uma anáfora associativa, nem sempre é fácil identificar a expressão que serve de âncora textual para uma descrição definida. Da mesma forma, nem sempre é uma tarefa fácil identificar a relação que uma descrição definida mantém com sua âncora. Haag \& Othero (2003) propõem o seguinte teste: quando desconfiarmos que uma descrição definida possa ser uma anáfora associativa, podemos substituí-la por um termo que seja de um campo semântico bem distante do significado de nossa suspeita descrição. Por exemplo: 
(26a) Entrei em um restaurante , e o $_{\text {garçom }}$ veio me atender.

Em (26a), suspeitamos que a descrição definida $o$ garçom esteja ancorada na expressão um restaurante. Para testarmos se nossa intuição está correta, faremos o que propõe o teste: trocaremos nossa descrição suspeita por uma de um campo semântico distinto e tentaremos estabelecer novamente a relação de anáfora associativa entre os dois termos:

(26b) ?? Entrei em um restaurante, e o lutador de sumo $\hat{o}_{\mathrm{r}}$ veio me atender.

Alterando a descrição definida o garçom por o lutador de sumô, percebemos que a relação de anáfora associativa se torna improvável, tornando estranha uma frase que pretenda manter tal relação anafórica (a não ser que imaginemos um universo onde lutadores de sumô atendam em restaurantes nunca, é claro, devemos subestimar a imaginação humana). De acordo com o teste, se a troca da descrição definida suspeita por uma de um campo semântico bem diferente (como a troca de o garçom por o lutador de sumô) for mal sucedida, tornando a sentença inaceitável no que concerne à sua relação anafórica, então a suspeita inicial estava certa: há uma relação de anáfora associativa entre a descrição e a âncora suspeitas.

Apesar de a resolução de uma anáfora associativa não ser, como dissemos, uma tarefa fácil, tentaremos sistematizar o maior número de casos possíveis em que esse tipo de anáfora acontece no português. Acreditamos que quanto mais pistas empíricas houver entre âncora e termo anafórico, mais fácil ficará para se trabalhar com a resolução de anáforas desse tipo em ambiente computacional, por exemplo.

\subsubsection{Hiperonímia}

O processo de hiperonímia, como vimos, consiste em introduzir um termo geral para então fazer referência a um termo mais específico, subordinado, de certa forma, ao termo geral. Em uma anáfora associativa por hiperonímia, a descrição definida é um termo mais particular que sua âncora textual. Aâncora é sobreordenada em relação à sua anáfora. Para Fávero (1997, p. 24), nessa relação, "o primeiro elemento mantém com o segundo uma relação todo-parte, classe-elemento". Exemplos: 
(27) As mais prestigiadas revistas de ciência do mundo vêm dando cada vez mais espaço para a cobertura de escândalos do mundo acadêmico, preocupadas também que alguns desses casos terminem respingando na credibilidade de suas publicações. Na revista americana Science, por exemplo, o tema scientific misconduct (imposturas científicas) já ganhou uma seção fixa. (SUP)

(28) Eles enfeitaram as mesas com muitas flores: as rosas $_{\mathrm{r}}$ estavam no arranjo central, as tulipas s $_{\mathrm{r}}$ sobre as cadeiras e as $_{\text {orquídeas }}$ ao lado dos pratos. (Exemplo de Haag \& Othero, 2003, p. 6.)

No exemplo (27), a descrição definida a revista americana Scienceé um exemplar do conjunto mais geral de revistas prestigiadas de ciência do mundo, que lhe serve de âncora textual. Em (28), a âncora textual tem a propriedade semântica de reunir em uma classe as descrições definidas que seguem (as rosas, as tulipas e as orquídeas).

\subsubsection{Hiponímia}

Como já vimos, em um processo de hiponímia, primeiro o locutor insere um termo mais específico no discurso, que servirá de âncora textual para uma descrição definida que é apresentada por uma expressão mais geral, em uma relação parte/todo. Em outras palavras, a âncora textual tem como nome-núcleo um item lexical que apresenta essa relação parte/todo com seu termo anafórico. A descrição definida vem a ser, então, um hiperônimo de sua âncora, enquanto esta é seu hipônimo. Exemplos:

(29) Eu estava em Nova York quando os americanos invadiram Granada e lembro a indignação do homem-âncora de um dos noticiários da $T V_{\mathrm{a}}$ - não com a invasão, com fato de o trabalho da imprensa $a_{\mathrm{r}}$ estar sendo dificultado pelos militares. (LFV1)

(30) Ao capturar o líder humano (...) Smith confessa que tudo o que ele quer é largar o emprego o quanto antes para ficar longe do vírus $d a$ humanidade . Do ponto de vista biológico, a comparação de Smith não é descabida. Até onde sabemos, os vírus r $_{\mathrm{r}}$ e diferenciam de outros micro-organismos por um comportamento autodestrutivo. (SUP) 
Em (29), um termo mais específico o homem-âncora de um dos noticiários da $T V$ ancora semanticamente a descrição definida a imprensa, que é seu hiperônimo. Em (30), um fenômeno curioso acontece: mesmo tendo nomesnúcleo iguais (vírus), os dois termos que compõem a anáfora não são correferentes, ou seja, eles não se referem à mesma entidade. Há uma relação de específico/ geral entre eles. A âncora textual se refere a um vírus específico, enquanto sua anáfora associativa se refere a todos os tipos de vírus.

\subsubsection{Nominalização}

Em um processo de nominalização, a descrição definida é um substantivo derivado de um verbo ou de um adjetivo que já tenha sido mencionado no discurso. Exemplos:

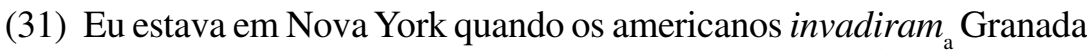
e lembro a indignação do homem-âncora de um dos noticiários da TV - não com a invasão, com fato de o trabalho da imprensa estar sendo dificultado pelos militares. (LFV1)

(32) Ele criou a teoria dos jogos na década de 40 para ajudar na formulação de estratégias para os EUA na Guerra Fria e chegou a recomendar que a União Soviética fosse atacada antes que se tornasse capaz de fabricar bombas nucleares. Era o racional a fazer. Eu sei, parece meio cínico ${ }_{\mathrm{a}}$, mas tem muito a ver com campanhas eleitorais, por exemplo - e não apenas por causa do cinismo. . $^{(\mathrm{REX})}$

Em (31), a invasão é a nominalização do verbo invadir; em (32), o cinismo é a nominalização do adjetivo cínico.

\subsubsection{Antonímia}

Em uma relação de anáfora associativa por antonímia, a descrição definida apresenta uma relação antonímica com algum termo anterior. Exemplos:

(33) O sistema promete reconhecer a caligrafia cursiva do usuário, o que facilita a entrada de dados: basta redigi-los na tela usando a caneta embutida no aparelho. Infelizmente, o reconhecimento cursivo é imperfeito e não entende textos em português. A solução é usar o teclado virtual ou recorrer à escrita por caracteres, que identifica uma letra de cada vez e dá melhores resultados. (FSP) 
(34) Eram assim as pazes ${ }_{\mathrm{a}}$; imagine a guerra $_{\mathrm{r} .}$ (MA)

As descrições definidas a escrita por caracteres, e a guerra, nos exemplos (33) e (34), estão semanticamente ancoradas em termos antonímicos que as precedem, a saber, a caligrafia cursiva e as pazes respectivamente.

\subsubsection{Papéis Temáticos do Verbo}

Tendo em mente a teoria dos papéis temáticos do verbo, nesse tipo de anáfora, consideramos que a descrição definida preenche o papel temático de um verbo anterior ${ }^{15}$. Exemplos:

(35) John foi assassinado ontem. $O$ assassino fugiu $^{16}{ }^{16 x e m p l o ~ d e}$ CLARK, 1979, p. 417.)

(36) Eu queria fechar a porta quando Moretti saltou dos arbustos. Com

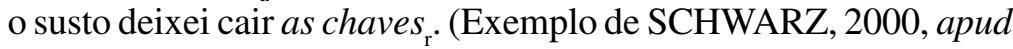
MARCUSCHI, 2001, p. 23.)

Em (35), o assassino é o agente do verbo que o ancora, assassinar. Em (36), a descrição definida as chaves cumpre o papel temático de instrumento do verbofechar mencionado na oração anterior.

\subsubsection{Modelos Cognitivos e Esquemas Mentais}

Nesse tipo de anáfora, a relação entre a descrição definida e sua âncora textual se estabelece baseada em representações conceituais ou modelos cognitivos globais. Aqui entram em jogo relações sofisticadas, como os frames, os esquemas, os planos, os scripts e os cenários. Um termo ou expressão anterior dispara na mente do interlocutor algum esquema mental que torna natural e clara a resolução anafórica de uma descrição definida que venha logo em seguida. É essencial para esse tipo de anáfora que o conhecimento enciclopédico do produtor do texto seja compartilhado com seu interlocutor.

Nesses casos, chegamos a um ponto que extrapola o conhecimento linguístico estrito, uma vez que fatores de ordem cognitiva e de conhecimento enciclopédico entram em jogo para a resolução da anáfora. Estamos, na verdade, em uma zona um tanto opaca, de intersecção entre o conhecimento linguístico e outros tipos de conhecimentos. Para Marcuschi (2001, p. 24), "não é fácil 
estabelecer distinções claras e rígidas entre conhecimentos conceituais armazenados na memória e conhecimentos semânticos lexicalizados, pois essas fronteiras são tênues e não há um sistema que se dê naturalmente". Exemplos:

(37) A vida, Janjão, é uma enorme loteria a $_{\mathrm{a}}$ Os prêmios $_{\mathrm{r}}$ são poucos, os malogrados $_{\mathrm{r}}$ inúmeros, e com os suspiros de uma geração é que se amassam as esperanças de outra. (MA)

(38) $O$ concorde a subiu. Os sistemas de segurança do avião detectaram então que a origem do fogo eram as turbinas - e não o tanque -, o que fez o piloto ${ }_{\mathrm{r}}$ desligá-las e tentar um pouso de emergência com os motores que sobravam. (SUP)

(39) Fui a um casamento ontem. A noiva ${ }_{\mathrm{r}}$ estava linda, e a decoração ${ }_{\mathrm{r}}$, impecável. (Exemplo de HAAG \& OTHERO, 2003, p. 10.)

Nesses exemplos, as âncoras textuais disparam na mente do interlocutor algum tipo de frame ou esquema mental que possibilita a fácil compreensão da descrição definida, bem como o estabelecimento da relação de anáfora associativa entre esta e sua âncora. Nesses casos, as associações são menos ligadas ao léxico do que nos outros tipos de anáforas associativas que estudamos até aqui. Elas dependem do conhecimento de mundo compartilhado entre locutor e interlocutor.

\subsection{Anáfora Conceitual}

A anáfora conceitual, às vezes também conhecida como anáfora resumitiva, geralmente aponta para uma porção textual e não para um referente ou objeto de discurso propriamente dito, como acontece com os outros tipos de anáforas estudados até aqui. Esse tipo de anáfora resume em um sintagma nominal um conceito, uma ideia ou um trecho do discurso.

Para Descombes-Dénérvaud \& Jespersen (1992), a anáfora conceitual é um processo de nominalização que nos permite sintetizar - ou resumir-em um SN um segmento de discurso com comprimento variável; pode ser um sintagma verbal, uma frase, um parágrafo ou mesmo um texto inteiro. Além de esse SN poder ser uma descrição definida (que é o nosso foco de estudo neste artigo), esse sintagma nominal pode aparecer como um SN demonstrativo (esse $N$ ) ou ainda como um SN que começa com artigo indefinido $(u m N)$. 
Na nominalização da anáfora conceitual, a descrição definida não retoma uma entidade do discurso (como acontece nos processos de anáfora direta e valorativa), nem está ancorada em uma expressão anterior (como acontece com a anáfora associativa). Enquanto na anáfora associativa temos uma descrição definida ancorada em uma expressão anterior no texto, na anáfora conceitual a descrição definida substitui (ou aponta para) um trecho anterior (em casos de anáfora) ou mesmo posterior no texto (em casos de catáfora). Além disso, a anáfora conceitual não se refere a uma entidade ou objeto de discurso, mas a uma porção textual.

De acordo com Guimarães (1993, p. 33), na anáfora conceitual

não se retoma um termo do enunciado precedente; antes, este é substituído por um enunciado que interpreta o que se disse antes. Assim, o avanço do discurso se opera por força de uma recapitulação interpretativa - procedimento de "economia" ou condensação que alivia a carga linguística dos elementos de retomada, ao mesmo tempo em que se preserva a unidade de conteúdo do texto. (Grifos nossos.)

Esse tipo de nominalização geralmente tem um caráter meramente metalinguístico. Em outras palavras, a descrição definida retoma um trecho anterior e vem expressa através de nomes "metalinguísticos" com sentido próprio, como a frase, a resposta, a pergunta, a sentença, a questão, o termo, a palavra, o parágrafo, etc., sem que haja um direcionamento argumentativo marcante do locutor do texto. Exemplo: ${ }^{17}$

(40) Aristóteles aponta o milésio Tales como iniciador da filosofia. Ora, Tales afirmou que no princípio era água $a_{\mathrm{E}}$. A resposta AC $_{\text {nos }}$ parece estranha, mas não a lembramos pelo conteúdo e sim pelo método que inventou. (DS)

Há, no entanto, casos em que a anáfora conceitual envolve aspectos inferenciais na retomada discursiva. Esses casos são mais complexos, porque a nominalização de uma porção textual deixa de ser meramente metalinguística e passa a rotular a informação recuperada com base em alguma inferência do próprio locutor do texto. Consequentemente, isso implica, em maior ou menor grau, um posicionamento argumentativo do locutor e um direcionamento argumentativo na construção de sentidos do texto. Adotamos aqui a classificação originalmente proposta por Koch (1999): 
a) Nomes ilocucionários: a ordem, a promessa, o conselho, a advertência, etc.

b) Nomes de atividades linguageiras: a descrição, a explicação, o relato, $o$ exemplo, a comparação, etc.

c) Nomes de processos mentais: a análise, a suposição, a atitude, a crença, etc.

Exemplos:

(41) Melhorar esses números ${ }_{\mathrm{E}}$ seria o grande objetivo de Meirelles para este ano. Mas é possível que o desafio ${ }_{\mathrm{AC}}$ seja bem diferente - ele está prestes a encarar uma campanha eleitoral. (REX)

(42) O Brasil está no rumo certo e a política econômica vai bem, mas $o$ País continua vulnerável a mudanças de humor nos mercados ${ }_{\mathrm{E}}$. A advertência ${ }_{\mathrm{AC}}$ foi feita pelo Fundo Monetário Internacional (FMI), no relatório sobre Perspectivas Econômicas Mundiais, e reiterada pelo economista-chefe da Instituição, Kenneth Rogoff, numa entrevista em Dubai. (ESP)

Nesses exemplos, o locutor do texto utiliza a anáfora conceitual para dar uma direção argumentativa ao leitor: ele mesmo (o locutor) faz a análise do que narrou e resume com uma descrição definida de maneira a deixar transparecer seu ponto de vista, orientando o leitor para o sentido que deseja transmitir ou construir. Assim, em (41), melhorar os números da empresa representa um desafio; e, em (42), o País continua vulnerável a mudanças de humor nos mercados deve ser encarado como uma advertência do FMI.

Há ainda casos mais sutis de anáforas conceituais, em que a descrição definida não exatamente substitui uma porção textual anterior, mas pressupõe que o leitor tenha feito uma inferência com base nessa porção textual, ou direciona o leitor para que faça essa inferência por meio disso. Vejamos os seguintes exemplos:

(43) Maior do que a dor de cabeça dos estudantes para decorar a tabela periódica foi a dificuldade que Mendeleiev teve em montá-la. Embora tivesse todas as informações das quais precisava - os elementos químicos e suas propriedades -, o químico russo não conseguia distribuí-los de maneira ordenada $a_{\mathrm{E}}$. Até que um sonho lhe trouxe $a$ solução ${ }_{\mathrm{AC}}$. (SUP)

(44) O sistema promete reconhecer a caligrafia cursiva do usuário, o que facilita a entrada de dados: basta redigi-los na tela usando a caneta 
embutida no aparelho. Infelizmente, o reconhecimento cursivo é imperfeito e não entende textos em português $\mathrm{E}_{\mathrm{E}}$. A solução ${ }_{\mathrm{AC}}$ é usar o teclado virtual ou recorrer à escrita por caracteres, que identifica uma letra de cada vez e dá melhores resultados. (FSP)

Nesses casos, a descrição definida não substitui um trecho anterior, mas está ancorada nele e na sua interpretação "correta" por parte do interlocutor. Utilizando-se desse recurso da anáfora conceitual, o locutor direciona a compreensão do texto de maneira ainda mais argumentativa - deixando transparecer seu ponto de vista mais claramente -, porém, ao mesmo tempo, muito mais sutil. $\mathrm{O}$ uso da descrição definida depende de que o leitor interprete o sentido de um trecho anterior da maneira como o locutor está indicando.

Assim, em (43), a descrição definida a solução não retoma o trecho não conseguia distribuí-los de maneira ordenada, já que isso não é uma solução. Antes, ela depende de que o leitor interprete esse trecho como sendo um problema, para então poder estar ancorada nessa interpretação. Arriscamo-nos a sugerir que essa estratégia força o leitor a interpretar o trecho como deseja o locutor, para que o uso da descrição definida possa ser justificado.

Em (44), vemos o mesmo processo. O uso da descrição definida $a$ solução se justifica por ela estar ancorada em uma interpretação do trecho destacado - infelizmente, o reconhecimento cursivo é imperfeito e não entende textos em português. Isso não é uma solução, mas um problema. $\mathrm{O}$ uso da descrição definida a solução está ancorada na inferência que o leitor faz de que o trecho destacado é um problema.

\section{Considerações Finais}

O fenômeno da anáfora na linguagem é bastante complexo, pois envolve diferentes estratégias linguísticas, tanto do locutor como do seu interlocutor. Nem sempre é uma tarefa fácil sistematizar a maneira como a resolução anafórica acontece, mas nossa proposta tentou esboçar de maneira abrangente uma classificação do uso das descrições definidas envolvidas em processos anafóricos. Vimos que há casos aparentemente menos complexos, como os de anáfora direta; casos com um certo grau de complexidade, como as anáforas valorativas; e casos que envolvem processos mais sofisticados, como os casos de anáforas associativas e conceituais. 


\section{Notas}

${ }^{1}$ Agradeço aos comentários feitos pelo parecerista anônimo desta revista sobre o texto.

${ }^{2}$ Esse conceito de "descrições definidas" é baseado em Russel (1905) e diversos trabalhos posteriores.

${ }^{3}$ Cf., por exemplo, Rocha Lima (1984, p. 84) e Cegalla (1996, p. 480). Contudo, alguns trabalhos baseados em corpora em língua inglesa (Vieira (1998), Poesio \& Vieira (1998), Gundel et al. (2001), por exemplo) e um aplicado à língua portuguesa (cf. projeto ANACORT [http://www.inf.unisinos.br/ renata/Ana_Introducao.html]) provaram que isso não é verdadeiro: aproximadamente $50 \%$ das descrições definidas podem ser classificadas como novas no discurso (conforme classificação de Vieira (1998)), introduzindo um referente novo ao contexto discursivo.

${ }^{4}$ Cf. Apêndice.

${ }^{5}$ Entendemos a correferenciação como um elemento da coesão referencial em que duas expressões no texto fazem remissão à mesma entidade discursiva.

${ }^{6} \mathrm{O}$ índice referencial $i$ subscrito indica que a descrição definida está se referindo ao mesmo objeto de discurso que também leva índice de igual valor, i. e., as expressões com o mesmo índice têm o mesmo referente discursivo.

${ }^{7}$ Uma ressalva: Marcuschi considera "anáforas diretas" tanto aquelas que chamamos de anáforas diretas quanto aquelas que chamaremos de anáforas valorativas.

${ }^{8}$ Esse tipo de anáfora também é conhecido na literatura como anáfora indireta, anáfora infiel ou ainda anáfora epitêtica.

${ }^{9}$ Essa diferença lexical entre o termo anafórico e seu antecedente torna o processamento anafórico muito mais complexo em termos computacionais, uma vez que um programa de resolução automática de anáforas perde a pista evidente da semelhança do nome núcleo. Cf. Poesio \& Vieira (1998), Vieira (1998), Vieira et al. (2002) e Gasperin et al. (2004), por exemplo.

${ }^{10}$ Sobre verbos valorativos, cf. Moura (2000), por exemplo.

${ }^{11}$ Exemplo original: I met a man yesterday. The bastard stole all my money. Clark (1979) chama este tipo de retomada anafórica de "anáfora epitêtica" (epithets).

${ }^{12}$ Cf. Ilari \& Geraldi (1994) e Fávero (1997), por exemplo.

${ }^{13} \mathrm{Na}$ verdade, ficaria estranho se BC aparecesse antes de Banco Central nesse exemplo.

${ }^{14}$ Seguindo as propostas de Fraurud (1990) e Marcuschi (2001). 
${ }^{15}$ Para saber mais sobre a teoria dos papéis temáticos, cf. Mioto et al. (2004), por exemplo.

${ }^{16}$ Exemplo original: John was murdered yesterday. The murderer got away.

${ }^{17}$ Para marcar visualmente a relação de anáfora conceitual, decidimos assinalar com um ${ }_{\mathbf{E}}$ subscrito (de Enunciado) a porção textual ou enunciado que é substituída pelo termo anafórico, e com um ${ }_{\text {AC }}$ subscrito (de Anáfora Conceitual) a descrição definida que funciona como termo anafórico.

\section{Referências}

CEGALLA, D. P. Novíssima gramática da língua portuguesa. São Paulo: Nacional, 1996.

CLARK, H. H. Bridging. In: JOHNSON-LAIRD, P. N.; WASON, P. C. (Eds.). Thinking: readings in cognitive science. London: Cambridge University Press, 1979.

DESCOMBES-DÉNÉRVAUD, M.; JESPERSEN, J. L'anaphore conceptualle dans l'argumentation écrite. Pratiques 73, março, 1992.

FÁVERO, L. Coesão e coerência textuais. São Paulo: Ática, 1997.

FRAURUD, K. Definiteness and the processing of NPs in natural discourse. Journal of Semantics, 7, 1990.

GASPERIN, C. et al. How useful are similarity word lists for indirect anaphora resolution? Proceedings of DAARC 2004, São Miguel, Azores, 2004.

GUIMARÃES, E. A articulação do texto. São Paulo: Ática, 1993.

GUNDEL, J. et al. Definite descriptions and cognitive status in English: why accommodation is unnecessary. English Language and Linguistics, n. 5, 2001.

HAAG, C. R.; OTHERO, G. A. Anáforas associativas nas análises das descrições definidas. Revista Virtual de Estudos da Linguagem - ReVEL. v. 1, n. 1, agosto 2003. [www.revel.inf.br].

ILARI, R.; GERALDI, J. W. Semântica. São Paulo: Ática, 1994.

KOCH, I. V. O texto e a construção dos sentidos. São Paulo: Contexto, 1997.

KOCH, I. V. Expressões referenciais definidas e sua função textual. In: DUARTE, L. P. (Org.). Para sempre em mim: homenagem a Ângela Vaz Leão. Belo Horizonte: CESPUC, 1999.

MARCUSCHI, L. A. Anáfora indireta: o barco textual e suas âncoras. Revista Letras, Curitiba, n. 56, 2001. 
MIOTO, C. et al. Novo manual de sintaxe. Florianópolis: Insular, 2004.

MOURA, H. Significação e contexto: uma introdução a questões de semântica e pragmática. Florianópolis: Insular, 2000.

POESIO, M.; VIEIRA, R. Corpus-based investigation of definite description use. Computational Linguistics, v. 24, n. 2, 1998.

ROCHA LIMA, C. H. Gramática normativa da língua portuguesa. Rio de Janeiro: José Olympio, 1984.

RUSSEL, B. On Denoting. Mind. v. 14, n. 56, 1905.

SCHWARZ, M. Indirekte Anaphern in Texten. Studien zur domängebundenen Referenz und Kohärenz im Deutschen. Tübingen, Niemeyer, 2000.

VIEIRA, R. Definite description processing in unrestricted text. Tese (Doutorado em Ciências da Computação). Centre for Cognitive Sciences, Edinburgh University. Edinburgh, 1998.

VIEIRA, R. et al. Coreference and anaphoric relations of demonstrative noun phrases in multilingual corpus. Proceedings of DAARC 2002, Portugal, 2002.

\section{Apêndice - Textos que constituíram o corpus da pesquisa}

DS SCHÜLER, Donaldo. Literatura grega. Porto Alegre: Mercado Aberto, 1985.

FAB FRANÇA, M.; FRANÇA, E. O burro na pele do leão. (s.l.), (s.d.).

FSP Jornal Folha de São Paulo. São Paulo, quarta-feira, 17 de julho de 2002.

LFV1 VERISSIMO, L. F. Comédias da vida pública: 266 crônicas datadas. Porto Alegre: L\&PM, 1997.

LFV2 VERISSIMO, L.F. A mãe do Freud. Porto Alegre: L\&PM, 1986.

MA ASSIS, M. Contos. Rio de Janeiro: Paz e Terra, 1997.

RCG REVISTACOMPUTER GAMES. Ano 1, n. 1. São Paulo: Sigla, 1993.

REX REVISTAEXAME. Ano 36, n. 9, maio. São Paulo: Abril, 2002.

SUP REVISTASUPERINTERESSANTE. Edição 178, julho. São Paulo: Abril, 2002. 